ARTICLE

\title{
Single-atom Pt in intermetallics as an ultrastable and selective catalyst for propane dehydrogenation
}

Yuki Nakaya1, Jun Hirayama 2,3, Seiji Yamazoe ${ }^{2,3,4}$, Ken-ichi Shimizu ${ }^{1,3}$ \& Shinya Furukawa (1,3,4凶

Propylene production via propane dehydrogenation $(\mathrm{PDH})$ requires high reaction temperatures to obtain sufficient propylene yields, which results to prominent catalyst deactivation due to coke formation. Developing highly stable catalysts for PDH without deactivation even at high temperatures is of great interest and benefit for industry. Here, we report that singleatom Pt included in thermally stable intermetallic PtGa works as an ultrastable and selective catalyst for PDH at high temperatures. Intermetallic PtGa displays three-hold-Pt ensembles and single Pt atoms isolated by catalytically inert $\mathrm{Ga}$ at the surface, the former of which can be selectively blocked and disabled by $\mathrm{Pb}$ deposition. The $\mathrm{PtGa}-\mathrm{Pb} / \mathrm{SiO}_{2}$ catalyst exhibits $30 \%$ conversion with $99.6 \%$ propylene selectivity at $600^{\circ} \mathrm{C}$ for $96 \mathrm{~h}$ without lowering the performance. The single-atom Pt well catalyzes the first and second $\mathrm{C}-\mathrm{H}$ activation, while effectively inhibits the third one, which minimizes the side reactions to coke and drastically improves the selectivity and stability.

\footnotetext{
${ }^{1}$ Institute for Catalysis, Hokkaido University, N21, W10, Sapporo 001-0021, Japan. ${ }^{2}$ Department of Chemistry, Graduate School of Science, Tokyo Metropolitan University, Hachioji-shi, Tokyo 192-0397, Japan. ${ }^{3}$ Elements Strategy Initiative for Catalysts and Batteries, Kyoto University, Katsura, Kyoto 6158520, Japan. ${ }^{4}$ Japan Science and Technology Agency, PRESTO, Chiyodaku, Tokyo 102-0076, Japan. ${ }^{凶}$ email: furukawa@cat.hokudai.ac.jp
} 
$\mathrm{P}$ ropylene is one of the most important building blocks for the production of a wide range of chemicals, such as polymers, resins, surfactants, dyes, and pharmaceuticals ${ }^{1}$. The supply of propylene has been reduced because of the recent shift in feedstock for steam crackers from oil-based naphtha to shale-based ethane. Catalytic propane dehydrogenation (PDH) using $\mathrm{Pt}$ - or $\mathrm{Cr}_{2} \mathrm{O}_{3}$-based materials is a promising on-purpose technique to satisfy the increasing global demand of propylene production ${ }^{1-3}$. Owing to the endothermicity, high reaction temperatures (preferably $\geq 600{ }^{\circ} \mathrm{C}$ ) are required to obtain sufficient propylene yields. However, severe catalyst deactivation due to coke deposition and/or sintering is inevitable under such harsh conditions; therefore, the catalysts in practical use must be regenerated continuously or in short cycles. Although a number of literatures on catalytic PDH have been reported to this day, no catalyst that exhibits high catalytic activity, selectivity, and daylong stability at high temperatures $\left(\geq 600^{\circ} \mathrm{C}\right)$ has been developed to the best of our knowledge $\mathrm{e}^{1-5}$. Developing a catalyst to meet this demanding task is of a great challenge in pure and applied chemistry.

Generally, selectivity and stability in PDH are determined by the balance between whether the product propylene desorbs or undergoes undesired side reactions, such as further $\mathrm{C}-\mathrm{H}(\mathrm{C})$ scissions and the subsequent coke formation ${ }^{6-10}$. For Pt-based catalysts, Pt-Pt ensembles are known to be active for overdehydrogenation of propylene and its hydrogenolysis ${ }^{1}$. The isolation of $\mathrm{Pt}$ atoms is a promising strategy to inhibit these undesired side reactions in $\mathrm{PDH}^{11}$. For instance, alloying of active main metal (mostly Pt) with a certain inactive metal (mostly typical elements such as $\mathrm{Sn}$ ) has been a conventional approach to dilute Pt-Pt ensembles and enhance propylene selectivity and stability ${ }^{1}$. However, it is difficult to completely isolate Pt atoms by the conventional alloying approach. Single-atom ${ }^{12-15}$ and singleatom alloy ${ }^{11,16}$ catalysts are also effective tools to use isolated $\mathrm{Pt}$, where active metals are atomically dispersed on an oxide support and isolated by excess amount of 11 group metal like $\mathrm{Cu}$, respectively. However, it is difficult to apply them to hightemperature reactions such as PDH due to its insufficient thermal stability: Pt atoms ${ }^{17}$ or alloy nanoparticles ${ }^{11,16}$ without spatial separation ${ }^{13}$ are easily aggregated to form larger nanoparticles at very high temperatures.

A possible candidate to solve this challenge is single-atom-like isolated Pt included in thermally stable intermetallic compounds. For instance, the 1:1 compound of $\mathrm{Pt}$ and $\mathrm{Ga}$ with cubic $P 2{ }_{1} 3$ space group has thermal stability $\left(\Delta H_{\mathrm{f}}=-55.6 \mathrm{~kJ} / \mathrm{mol}^{-1}\right)$ much greater than typical random alloys $\left(-10<\Delta H_{\mathrm{f}} \leq\right.$ $0 \mathrm{~kJ} \mathrm{~mol}^{-1}$ ) and a unique structure for this purpose as shown in Fig. 1 (refs. ${ }^{18,19}$ ). The stable (111) surface of PtGa has four different terminations displaying isolated and threefold $\mathrm{Pt}$ and $\mathrm{Ga}$ sites (hereafter signed $\mathrm{Pt}_{1}, \mathrm{Ga}_{1}, \mathrm{Pt}_{3}$, and $\mathrm{Ga}_{3}$ ). Here, the $\mathrm{Ga}_{3}$ moiety can be regarded as a matrix to support the isolated $\mathrm{Pt}_{1}$ atom; therefore, it may be possible to describe the $\mathrm{Pt}_{1}$ site as "single-atom Pt". Note that there are two enantiomeric forms of PtGa unit cell (PtGa:A and PtGa:B, the former is shown in Fig. 1), because the space group $P 2{ }_{1} 3$ is chiral. In an analogous system of PdGa (space group $\left.P 2{ }_{1} 3\right)$, such surface termination $\left(\mathrm{Pd}_{3}\right.$ and $\mathrm{Pd}_{1}$, which were described as trimer and single atom, respectively) has actually been observed by surface science techniques ${ }^{20,21}$. For the $\mathrm{PdGa}$ system, $\mathrm{Pd}_{3}$ is known to catalyze semihydrogenation of acetylene more selectively than $\mathrm{Pd}_{1}$ (ref. ${ }^{20}$ ). For PtGa in $\mathrm{PDH}$, however, the $\mathrm{Pt}_{3}$ site is expected to be more active for further $\mathrm{C}-\mathrm{H}(\mathrm{C})$ scissions. Therefore, some modification that makes only $\mathrm{Pt}_{3}$ sites disabled while $\mathrm{Pt}_{1}$ sites available for the reaction is needed for achieving highly selective and stable PDH.

In this study, we design $\mathrm{Pb}$-modified $\mathrm{PtGa}$ where the threefold $\mathrm{Pt}$ is selectively blocked by $\mathrm{Pb}$ deposition while the single-atom $\mathrm{Pt}$

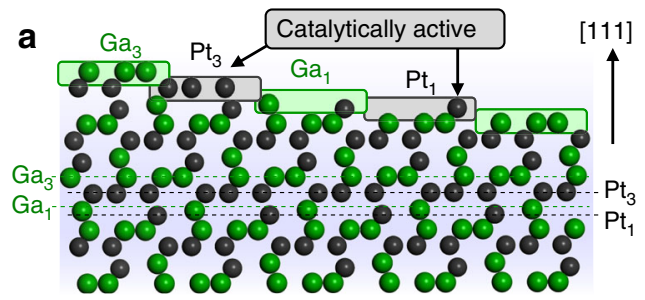

b

PtGa:A(111)-Pt

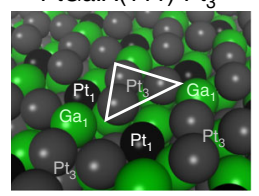

PtGa:A(111)-Pt

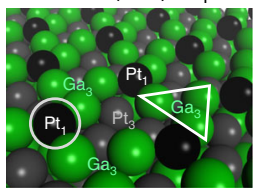

c

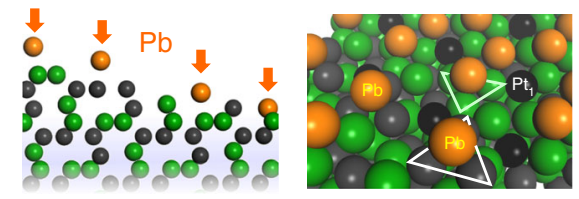

Fig. 1 Catalyst design of single-atom Pt in PtGa. a Four different surface terminations of PtGa:A(111) viewed along [101] direction (ball model). b Diagonal view of $\mathrm{Pt}_{3}$ and $\mathrm{Pt}_{1}$ termination (space-filling model). $\mathrm{Pt}_{1}$ is highlighted with black color. c Catalyst design by $\mathrm{Pb}$ deposition to block the $\mathrm{Pt}_{3}$ (and $\mathrm{Ga}_{3}$ ) sites and to keep the $\mathrm{Pt}_{1}$ sites available.
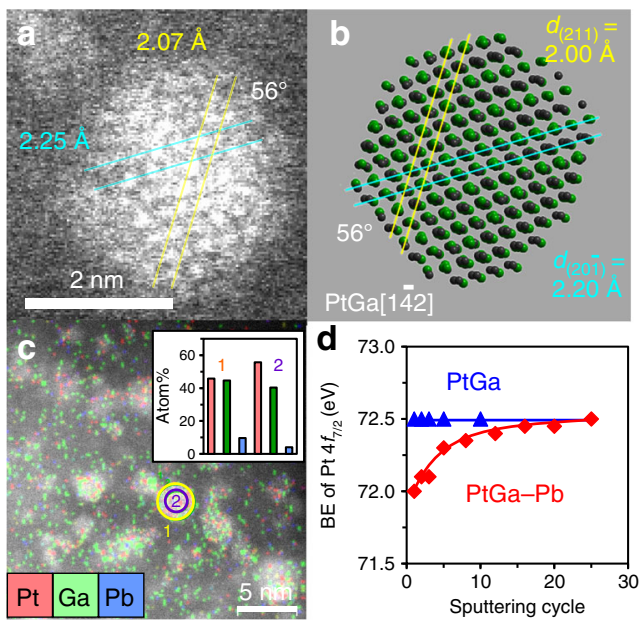

Fig. $\mathbf{2}$ Characterization of $\mathbf{P t G a}-\mathbf{P b} / \mathbf{S i O}_{2}$. a HAADF-STEM image of a single nanoparticle in $\mathrm{PtGa}-\mathrm{Pb} / \mathrm{SiO}_{2}(\mathrm{Pt} / \mathrm{Pb}=2)$. $\mathbf{b}$ Crystal structure of intermetallic PtGa viewed along [1ד̄2] direction. c Elemental map of Pt, Ga, and $\mathrm{Pb}$ acquired by EDX. Inset shows their atom\% included in areas 1 (yellow circle) and 2 (purple circle), corresponding to the whole and core region of a single nanoparticle. $\mathbf{d}$ Changes in $\mathrm{Pt} 4 f_{7 / 2}$-binding energy (BE) of $\mathrm{PtGa} / \mathrm{SiO}_{2}$ and $\mathrm{PtGa}-\mathrm{Pb} / \mathrm{SiO}_{2}(\mathrm{Pt} / \mathrm{Pb}=2)$ during sputtering cycles.

remains intact (Fig. 1c). As demonstrated later, the convex $\mathrm{Pt}_{1}$ site is unfavorable geometrically and energetically for $\mathrm{Pb}$ deposition. We prepare $\mathrm{SiO}_{2}$-supported $\mathrm{PtGa}$ and $\mathrm{PtGa}-\mathrm{Pb}(\mathrm{Pt} / \mathrm{Pb}=2)$ catalysts by an impregnation method (reduced by $\mathrm{H}_{2}$ at $700{ }^{\circ} \mathrm{C}$ ) and test in $\mathrm{PDH}$ at high temperatures $\left(600\right.$ or $650^{\circ} \mathrm{C}$; note that it is lower than the preparation temperature). Here, we show a different type of single-atom Pt and its outstandingly high catalytic performance in $\mathrm{PDH}$ at high temperature.

\section{Results}

Characterization of catalysts. Figure $2 \mathrm{a}$ shows the highresolution high-angle annular dark field scanning transmission 
electron microscopy (HAADF-STEM) image of $\mathrm{PtGa}-\mathrm{Pb} / \mathrm{SiO}_{2}$ with a single nanoparticle. A crystal structure with interplanar distances of 2.07 and $2.25 \AA$ and dihedral angle of $56^{\circ}$ was observed, which agreed with those of (211) and (201) planes of intermetallic PtGa viewed along with [14̄2] direction 22 (Fig. 2b). The particle size distribution was narrow (mostly $1.5-3 \mathrm{~nm}$, Supplementary Fig. 1) with an average of $2.8 \pm 0.6 \mathrm{~nm}$. The elemental map acquired by energy-dispersive X-ray (EDX) analysis showed that Pt and Ga were homogeneously distributed in each nanoparticle with approximately 1:1 ratio (Fig. 2c). Similar results of the HAADF-STEM-EDX analyses were also obtained for $\mathrm{PtGa} / \mathrm{SiO}_{2}$ (Supplementary Fig. 2, Supplementary Note 1). On the contrary, the $\mathrm{Pb}$ distribution in $\mathrm{PtGa}-\mathrm{Pb} / \mathrm{SiO}_{2}$ was focused on the shell part of nanoparticles (areas 1 and 2 in Fig. 2c). Considering that the $\mathrm{Pb}$ content in the whole nanoparticle (area 1) is lower than those fed in the catalyst $(\mathrm{Pt} / \mathrm{Pb}=2)$, a part of $\mathrm{Pb}$ may present on $\mathrm{SiO}_{2}$ support. X-ray photoelectron spectroscopy (XPS) analysis with $\mathrm{Ar}^{+}$sputtering revealed that the $\mathrm{Pt} 4 f_{7 / 2}$-binding energy of $\mathrm{PtGa}-\mathrm{Pb}$ was lower than that of $\mathrm{PtGa}$ (due to ligand effect of $\mathrm{Pb})^{23}$, but came close immediately after several sputtering (Fig. 2d, see Supplementary Fig. 3 for the spectra). This result strongly supports that $\mathrm{Pb}$ is located at the surface region of $\mathrm{PtGa}$ nanoparticles. We also performed X-ray adsorption fine structure (XAFS) analysis (see Supplementary Notes 2 and 3, Supplementary Figs. 4-7, and Supplementary Table 1 for XAFS analysis: $\mathrm{Pt} \mathrm{L}_{\mathrm{III}}$-edge $\mathrm{X}$-ray adsorption near edge spectra, extended XAFS (EXAFS) raw oscillations, EXAFS curve fits, magnitude of Fourier transform of EXAFS, and details of the curve fit). Pt-Ga scattering with $2.50 \pm 0.01 \AA$ was observed for PtGa-Pb, which is consistent finely with the interatomic distance of the nearest $\mathrm{Pt}$ and $\mathrm{Ga}$ in $\mathrm{PtGa}(2.499 \AA)^{22}$. This result suggests that $\mathrm{Pb}$ atoms are not substituted into the bulk of PtGa to increase the lattice constant. $\mathrm{Pt}-\mathrm{Pb}$ scattering was also observed with a small coordination number of 1.0, which indicates that the surface $\mathrm{Pt}$ sites are partly blocked by $\mathrm{Pb}$ deposition. $\mathrm{CO}$ pulse chemisorption experiment supported the partial coverage of surface $\mathrm{Pt}$, where $\mathrm{Pt}$ dispersion decreased from $9.9 \%$ to $5.9 \%$ upon the $\mathrm{Pb}$ modification to $\mathrm{PtGa} / \mathrm{SiO}_{2}$ (Supplementary Table 2).

To obtain further information about the surface of $\mathrm{PtGa}-\mathrm{Pb} / \mathrm{SiO}_{2}$, we then performed Fourier-transform infrared (FT-IR) spectroscopy with $\mathrm{CO}$ adsorption at $-196^{\circ} \mathrm{C}$ (Fig. 3). For $\mathrm{PtGa} / \mathrm{SiO}_{2}$, two peaks appeared at 2078 and $1885 \mathrm{~cm}^{-1}$ at the initial stage, which are assigned to stretching vibration of $\mathrm{CO}$ adsorbed on Pt with on-top and threefold modes, respectively ${ }^{21}$. Upon the increase in CO pressure $\left(P_{\mathrm{CO}}\right)$, the threefold $\mathrm{CO}$ disappeared and the intensity of the on-top $\mathrm{CO}$ increased with an appearance of a small shoulder feature at around $2050 \mathrm{~cm}^{-1}$. This change could be attributed to the migration of threefold $\mathrm{CO}$ to on-top CO on the $\mathrm{Pt}_{3}$ site due to the increase of $\mathrm{CO}$ coverage. The new shoulder at around $2050 \mathrm{~cm}^{-1}$ might be assigned to on-top $\mathrm{CO}$ adsorbed on $\mathrm{Pt}_{1}$ site $^{21}$. On the contrary, for $\mathrm{PtGa}-\mathrm{Pb} / \mathrm{SiO}_{2}$, only a single symmetric adsorption band appeared at $2040 \mathrm{~cm}^{-1}$ with lower intensity even at saturation coverage, which implies that the $\mathrm{Pt}_{3}$ sites are blocked by $\mathrm{Pb}$ while the remaining $\mathrm{Pt}_{1}$ sites are open for $\mathrm{CO}$ adsorption. We then simulated the theoretical $v_{\mathrm{C}=\mathrm{O}}$ for the suggested conformations by density functional theory (DFT) calculations (see Supplementary Fig. 8 for the detailed structures and $v_{\mathrm{C}=\mathrm{O}}$ values). The calculated $v_{\mathrm{C}=\mathrm{O}}$ values were consistent finely (on-top CO) or roughly (threefold $\mathrm{CO}$ ) with the corresponding experimental values (Fig. 3, vertical lines), which strongly supports the assignment mentioned above. The observed trend agreed also with a relevant system of $\mathrm{CO}$ adsorption on PdGa:B(111) monitored by surface science techniques ${ }^{21}$. Only a slight red-shift in $v_{\mathrm{C}=\mathrm{O}}\left(2043\right.$ to $\left.2037 \mathrm{~cm}^{-1}\right)$ was suggested when $\mathrm{Pb}$ was added near the $\mathrm{Pt}_{1}$ site, likely because

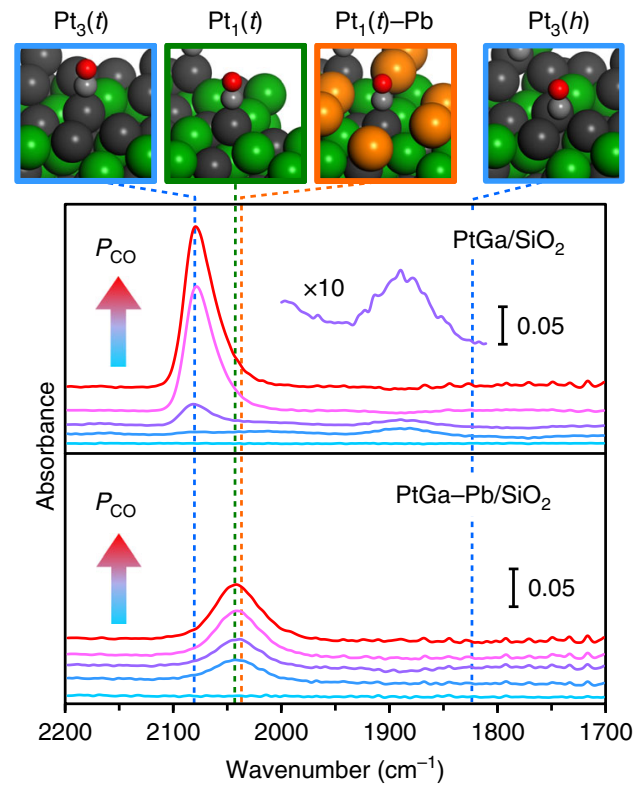

Fig. 3 Surface characterization by FT-IR with $\mathbf{C O}$ adsorption. Changes in FT-IR spectra of $\mathrm{CO}$ adsorbed on $\mathrm{PtGa} / \mathrm{SiO}_{2}$ and $\mathrm{PtGa}-\mathrm{Pb} / \mathrm{SiO}_{2}(\mathrm{Pt} / \mathrm{Pb}=$ 2) with increase in $P_{\text {CO }}$ measured at $-196^{\circ} \mathrm{C}$ are shown. Vertical dashed lines indicate $\nu_{\mathrm{C}=\mathrm{O}}$ values calculated by DFT. The upper pictures show the optimized structures of on-top $\mathrm{CO}(t)$ on $\mathrm{Pt}_{3}, \mathrm{Pt}_{1}$, and $\mathrm{Pt}_{1}-\mathrm{Pb}$ sites, and threefold $\mathrm{CO}(h)$ on $\mathrm{Pt}_{3}$ hollow site.
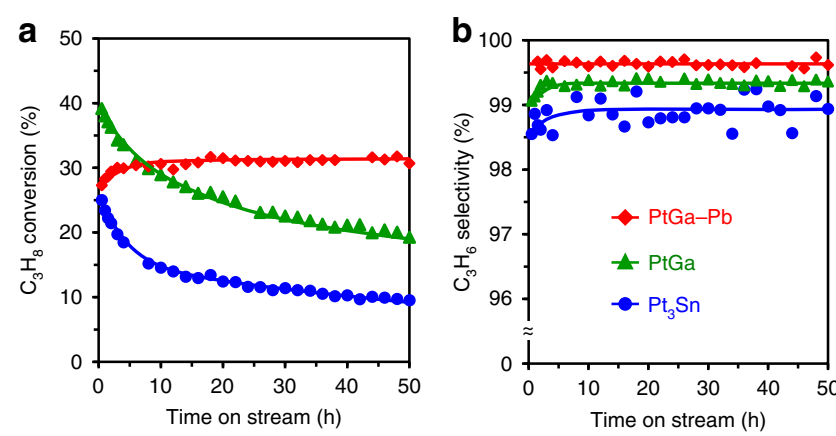

Fig. 4 Catalytic performance in PDH. a, b Changes in propane conversion (a) and propylene selectivity (b) in $\mathrm{PDH}$ catalyzed by $\mathrm{PtGa} / \mathrm{SiO}_{2}, \mathrm{PtGa}-\mathrm{Pb} /$ $\mathrm{SiO}_{2}(\mathrm{Pt} / \mathrm{Pb}=2)$, and $\mathrm{Pt}_{3} \mathrm{Sn} / \mathrm{SiO}_{2}$ are shown. Catalyst amount was adjusted so that the number of exposed Pt was identical $(4.5 \mu \mathrm{mol})$ : PtGa (9.0 mg), PtGa-Pb ( $\mathrm{Pt} / \mathrm{Pb}=2)(15 \mathrm{mg}), \mathrm{Pt}_{3} \mathrm{Sn}(3.7 \mathrm{mg})$, and diluted with quartz sand (total $1.5 \mathrm{~g}$ ). Gas feed: $\mathrm{C}_{3} \mathrm{H}_{8}: \mathrm{H}_{2}: \mathrm{He}=3.9: 5.0: 40 \mathrm{~mL} \mathrm{~min}^{-1}$. Temperature: $600^{\circ} \mathrm{C}$.

of electron-enriched $\mathrm{Pt}$ by the ligand effect of $\mathrm{Pb}$ as observed in Fig. 2d. Thus, we successfully prepared an ideal catalyst for PDH with single-atom-like isolated $\mathrm{Pt}$ without any $\mathrm{Pt}$-Pt ensembles.

Catalytic performance in PDH. Next, we tested the catalytic performances of the prepared catalysts in $\mathrm{PDH}$ at $600^{\circ} \mathrm{C}$ (Fig. 4), in which the equilibrium propylene yield in this reaction condition was approximately 60\% (Supplementary Fig. 9). Although $\mathrm{PtGa}$ exhibited high conversion and selectivity at the initial stage ( $40 \%$ conv., $99.1 \%$ sel. at $0.5 \mathrm{~h}$ ), conversion gradually decreased below half of its initial value within $50 \mathrm{~h}$. Conversely, $\mathrm{PtGa}-\mathrm{Pb}$ retained high conversion and excellent selectivity ( $>30 \%$ conv., $>99.6 \%$ sel.) for $50 \mathrm{~h}$ even under the harsh condition. It should be 
noted that almost no deactivation was observed even at $96 \mathrm{~h}$ (Supplementary Fig. 10). Thus, the $\mathrm{Pb}$ modification to $\mathrm{PtGa}$ significantly improved the stability and selectivity. We achieved the long-term, continuous, and highly selective propylene production in $\mathrm{PDH}$ at high temperatures without deactivation $(>580$ ${ }^{\circ} \mathrm{C}$ : see Supplementary Tables 3 and 4 and Supplementary Fig. 11 for comparison with literatures; deactivation rate constant was defined in Supplementary Note 4). We also tested $\mathrm{Pt}_{3} \mathrm{Sn}$ catalyst, the well-known catalyst selective for $\mathrm{PDH}^{1,7}$, which gave lower conversion, selectivity, and stability (higher deactivation rate, Supplementary Table 5) than PtGa, highlighting the outstandingly high catalytic performance of $\mathrm{PtGa}-\mathrm{Pb}$. The spent catalysts were then analyzed by temperature-programed oxidation (TPO) and the HAADF-STEM-EDX analysis. PtGa and $\mathrm{Pt}_{3} \mathrm{Sn}$ showed coke combustion peaks in their TPO profiles, while $\mathrm{PtGa}-\mathrm{Pb}$ gave no peak (Supplementary Fig. 12). This is consistent with the stability trend in Fig. 4 and suggests that the coke formation process is strictly inhibited. The HAADF-STEM-EDX analysis revealed that, despite the long-term operation $(50 \mathrm{~h})$ in the harsh condition, $\mathrm{PtGa}-\mathrm{Pb}$ retained its small particles sizes (flesh: $2.8 \pm 0.6 \mathrm{~nm}$, spent: $3.0 \pm 0.6 \mathrm{~nm}$ ), intermetallic structure, and elemental distribution (Supplementary Fig. 13, Supplementary Note 5), demonstrating the high thermal stability and resistance to sintering. The stability test was also conducted at $650{ }^{\circ} \mathrm{C}$, where $\mathrm{PtGa}-\mathrm{Pb}$ retained high conversion (37-38\%) for several hours and then gradually decreased to approximately $20 \%$ over $50 \mathrm{~h}$ (Supplementary Note 6, Supplementary Fig. 14). The gradual deactivation can be attributed to the contribution of thermal (noncatalytic) cracking ${ }^{24}$. This was confirmed by a control experiment using $\mathrm{SiO}_{2}$, in which small amount of $\mathrm{C}_{1}$ and $\mathrm{C}_{2}$ were formed at $650{ }^{\circ} \mathrm{C}$, while that was negligible at $600^{\circ} \mathrm{C}$ (Supplementary Fig. 15). Other bimetallic combinations that have been reported to be effective for PDH (PtSn (ref. ${ }^{25}$ ) and $\mathrm{Pt}_{3} \mathrm{In}$ (ref. ${ }^{8}$ ); see Supplementary Note 7 and Supplementary Fig. 16 for details and their X-ray diffraction (XRD) patterns, respectively) were also tested at $600^{\circ} \mathrm{C}$. However, they all showed deactivation trends similar to that of $\mathrm{Pt}_{3} \mathrm{Sn}$ (Supplementary Fig. 17, Supplementary Table 5). Considering that $\mathrm{Pt}-\mathrm{Ga}(\mathrm{Pt} / \mathrm{Ga}=3)$ gave higher deactivation rate and lower selectivity than PtGa, using 1:1 PtGa phase is a significant factor to develop a highly efficient catalytic system for PDH (Supplementary Fig. 17, Supplementary Table 5). When the modifier for PtGa was changed from $\mathrm{Pb}$ to other metals such as In or Sn, no positive effects on activity and selectivity were obtained (Supplementary Fig. 14). We also tested the recyclability of $\mathrm{PtGa}-\mathrm{Pb}$ catalyst (Supplementary Note 8, Supplementary Fig. 18). The spent $\mathrm{PtGa}-\mathrm{Pb}$ catalyst could be regenerated by $\mathrm{O}_{2}$ treatment to recover the original catalytic performance after some induction period, whereas some other bimetallic or trimetallic Sn-containing catalysts $\left(\mathrm{Pt}_{3} \mathrm{Sn}\right.$, $\mathrm{PtSn}$, and PtGa-Sn) did not (Supplementary Fig. 19). Therefore, the combination of intermetallic PtGa and the $\mathrm{Pb}$ modification is suitable for stabilizing single-atom-like isolated Pt at high temperature. This is probably because (1) PtGa itself is thermodynamically stable $\left(\Delta H_{\mathrm{f}}=-55.6 \mathrm{~kJ} \mathrm{~mol}^{-1}\right)^{18,19}$ and (2) the atomic radius ${ }^{26}$ of $\mathrm{Pb}(1.80 \AA)$ is much larger than those of $\mathrm{Pt}$ $(1.35 \AA)$ and $\mathrm{Ga}(1.30 \AA)$ : the diffusion of $\mathrm{Pb}$ into the bulk of $\mathrm{PtGa}$ is likely to be unfavorable even at $600{ }^{\circ} \mathrm{C}$. Although several researchers have pointed that $\mathrm{Ga}$ works as a good promotor for Pt-based PDH as well as other typical element such as Sn or In (refs. ${ }^{27-33}$ ), our results indicate that the geometry and appropriate design of an active site is more significant rather than the individual chemical property of the additive element, that is, $\mathrm{Pt}$ should be strictly isolated. We also surveyed various $\mathrm{Pt} / \mathrm{Pb}$ ratios and metal oxides as catalyst supports, which confirmed that $\mathrm{PtGa}-\mathrm{Pb} / \mathrm{SiO}_{2}(\mathrm{Pt} / \mathrm{Pb}=2)$ was the best (Supplementary Notes 9 and 10, Supplementary Figs. 20 and 21). Ga itself has also been a
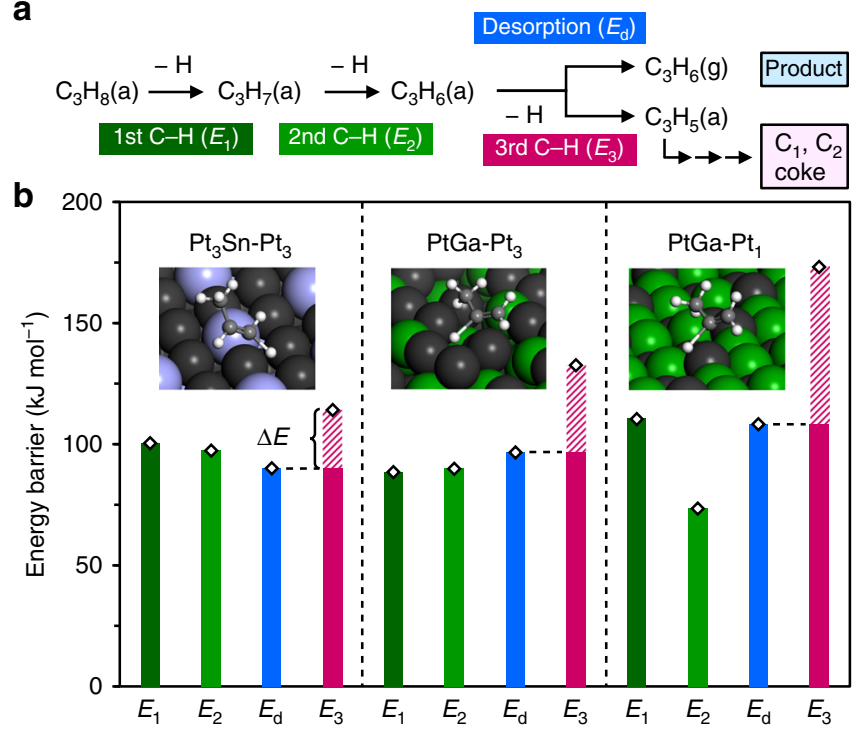

Fig. 5 Theoretical interpretation of propylene selectivity. a The reaction scheme of PDH to generate propylene and undesired products. $\mathbf{b}$ The energy barriers of each $\mathrm{C}-\mathrm{H}$ scission and propylene desorption on $\mathrm{Pt}_{3} \mathrm{Sn}$ (111)- $\mathrm{Pt}_{3}, \mathrm{PtGa}: \mathrm{A}(111)-\mathrm{Pt}_{3}$, and $\mathrm{PtGa}: \mathrm{A}(111)-\mathrm{Pt}_{3}$. Inset picture shows the transition state structure in the third $\mathrm{C}-\mathrm{H}$ scission for each surface. Dark green, light green, magenta, and cyan bars represent the activation energies for first $\left(E_{1}\right)$, second $\left(E_{2}\right)$, third $\left(E_{3}\right) \mathrm{C}-\mathrm{H}$ scissions, and propylene desorption $\left(E_{\mathrm{d}}\right)$, respectively. Shaded parts in magenta bars correspond to $\Delta E\left(\Delta E=E_{3}-E_{\mathrm{d}}\right)$.

known to be active for $\mathrm{PDH}^{34}$. However, a control experiment using $\mathrm{Ga} / \mathrm{SiO}_{2}$ at $650{ }^{\circ} \mathrm{C}$ (Supplementary Fig. 22) showed very low conversion $(<3 \%)$, indicating the negligible contribution of $\mathrm{Ga}$ itself to the catalysis of much more active Pt-based materials.

DFT calculations. Finally, we conducted DFT calculations for the step-wise $\mathrm{C}-\mathrm{H}$ scissions of propane to clarify the detailed property of isolated $\mathrm{Pt}$ for selective $\mathrm{PDH}$. Figure 5 summarizes the reaction scheme of $\mathrm{PDH}$ and the calculated energy barrier of each step $\left(E_{x}: x=1,2,3\right.$, and $d$; see Supplementary Figs. 23-25, Supplementary Fig. 26, and Supplementary Table 6 for the detailed structures, energy diagram, and summarized activation energies, respectively). The adsorbed propylene $\left(\mathrm{C}_{3} \mathrm{H}_{6}(\mathrm{a})\right)$ formed via the first and second $\mathrm{C}-\mathrm{H}$ scissions undergoes desorption to gas phase $\left(\mathrm{C}_{3} \mathrm{H}_{6}(\mathrm{~g})\right)$ or further (third) $\mathrm{C}-\mathrm{H}$ scission to trigger undesired side reactions ${ }^{6-10}$. Here, propylene selectivity depends on the difference in the two energy barriers $\left(\Delta E=E_{3}-E_{\mathrm{d}}\right.$, shaded part in Fig. 5): the larger $\Delta E$ is, the higher the selectivity is. $\mathrm{PtGa} \mathrm{Pt}_{3}$ gave $\Delta E$ of $35.9 \mathrm{~kJ} \mathrm{~mol}^{-1}$, which was slightly larger than that of $\mathrm{Pt}_{3} \mathrm{Sn}(111)\left(24.1 \mathrm{~kJ} \mathrm{~mol}^{-1}\right)$. Interestingly, $\mathrm{PtGa} \mathrm{Pt}_{1}$ having the isolated $\mathrm{Pt}$ showed much larger $\Delta E$ of $64.9 \mathrm{~kJ} \mathrm{~mol}^{-1}$. This is due to the remarkably high $E_{3}\left(173.2 \mathrm{~kJ} \mathrm{~mol}^{-1}\right)$ even though $E_{1}$ (typically the rate-determining step of $\mathrm{PDH}$ ) and $E_{\mathrm{d}}$ did not differ significantly from those of $\mathrm{PtGa}^{-\mathrm{Pt}_{3}}$ and $\mathrm{Pt}_{3} \mathrm{Sn}_{-} \mathrm{Pt}_{3}$ sites. The specifically high $E_{3}$ could be attributed to the molecular rotation from lying $1,2-\pi-\mathrm{C}_{3} \mathrm{H}_{6}$ to vertically standing $2-\sigma-\mathrm{C}_{3} \mathrm{H}_{5}$ conformations occurring at the convex $\mathrm{Pt}_{1}$ site (Supplementary Fig. 25c). Because of the molecular rotation and long Pt-Pt distance between the $\mathrm{Pt}_{1}$ site and the nearest neighboring $\mathrm{Pt}_{3}$ site $(3.06 \AA)$, the hydrogen atom involved in the third $\mathrm{C}-\mathrm{H}$ scission has to migrate a long distance toward the final state. The energy required for such an unfavorable path becomes significantly high. We also estimated the theoretical propylene selectivity based on 


\section{Table 1 Theoretical and experimental $\mathrm{C}_{3} \mathrm{H}_{6}$ selectivity in} $\mathrm{PDH}$ at $600{ }^{\circ} \mathrm{C}$.

\section{Theoretical simulation}

\begin{tabular}{|c|c|c|c|c|}
\hline Surface & $\Delta E\left(\mathrm{~kJ} \mathrm{~mol}^{-1}\right)^{\mathrm{a}}$ & $\begin{array}{l}\mathrm{C}_{3} \mathrm{H}_{6} \\
\text { sel. (\%) }\end{array}$ & Catalyst & $\begin{array}{l}\text { Initial } \mathrm{C}_{3} \mathrm{H}_{6} \\
\text { sel. }(\%)^{\mathbf{b}}\end{array}$ \\
\hline $\mathrm{Pt}_{3} \mathrm{Sn}-\mathrm{Pt}_{3}$ & 24.1 & 96.5 & $\mathrm{Pt}_{3} \mathrm{Sn} / \mathrm{SiO}_{2}$ & $98.6(97.5)^{c}$ \\
\hline $\mathrm{PtGa}-\mathrm{Pt}_{3}$ & 35.9 & 99.3 & $\mathrm{PtGa} / \mathrm{SiO}_{2}$ & 99.1 \\
\hline $\mathrm{PtGa} \mathrm{Pt}_{1}$ & 64.9 & $>99.9$ & $\begin{array}{l}\mathrm{PtGa}-\mathrm{Pb} / \\
\mathrm{SiO}_{2}\end{array}$ & 99.6 \\
\hline
\end{tabular}

a Difference between the activation energies of propylene desorption and the third $\mathrm{C}-\mathrm{H}$ scission. bAt $0.5 \mathrm{~h}$ of time on stream.

catalyst amount: $15 \mathrm{mg}$.

the Arrhenius equation with $\Delta E$ (see Supplementary Note 11 for details), which are listed in Table 1 with the corresponding experimental values. The calculated values and their order were consistent with the experimental results, which demonstrates the validity of our calculation model. Thus, our calculation successfully reproduced the experimental trends in selectivity. The high propylene selectivity of $\mathrm{Pt}_{1}$ sites minimizes the accumulation of coke, which leads to the outstandingly high catalyst stability. Finally, we investigated the affinity of $\mathrm{Pb}$ deposition to several $\mathrm{Pt}$ and $\mathrm{Ga}$ sites. $\mathrm{Pb}$ atoms adsorbed stably on the $\mathrm{Pt}_{3}, \mathrm{Ga}_{3}$, and concave $\mathrm{Pt}_{1}$ (in $\mathrm{PtGa} \mathrm{Pt}_{3}$ termination) sites with large adsorption energies ( -462 to $-337 \mathrm{~kJ} \mathrm{~mol}^{-1}$, Supplementary Fig. 27), while could not on the convex $\mathrm{Pt}_{1}$ site: the $\mathrm{Pb}$ atom placed on the top of the $\mathrm{Pt}_{1}$ site migrated downward during structure optimization. This result indicates that the convex $\mathrm{Pt}_{1}$ site is unfavorable for $\mathrm{Pb}$ deposition geometrically and energetically.

\section{Discussion}

In summary, we designed and prepared the $\mathrm{PtGa}-\mathrm{Pb} / \mathrm{SiO}_{2}$ catalyst for highly selective $\mathrm{PDH}$, in which threefold hollow $\mathrm{Pt}_{3}$ ensembles were successfully blocked by $\mathrm{Pb}$ deposition, while the single-atom-like isolated $\mathrm{Pt}_{1}$ sites remained. The isolated $\mathrm{Pt}_{1}$ is highly selective (99.6\%) for propylene production and the catalyst is outstandingly stable for long-term operation at high temperature $\left(96 \mathrm{~h}, 600^{\circ} \mathrm{C}\right)$. The catalytic performance in $\mathrm{PDH}$ is much superior to those of the reported systems. The combination of (1) the specific crystal structure of intermetallic PtGa providing isolated $\mathrm{Pt},(2)$ its thermal stability, and (3) the large atomic size of $\mathrm{Pb}$ enables the remarkably high selectivity and stability even in harsh conditions. The results obtained in this study provide not only a highly efficient catalytic system for alkane dehydrogenation but also significant insights for material design to isolate and stabilize active metals.

\section{Methods}

Materials. $\mathrm{SiO}_{2}\left(\right.$ CARiACT G-6, Fuji Silysia, $S_{\mathrm{BET}}=673 \mathrm{~m}^{2} \mathrm{~g}^{-1}$ ), $\mathrm{Al}_{2} \mathrm{O}_{3}$ (prepared by the calcination of boehmite $\left[\gamma-\mathrm{AlOOH}\right.$, supplied by SASOL chemicals] at $900{ }^{\circ} \mathrm{C}$ for $3 \mathrm{~h}, \gamma$-phase), $\mathrm{CeO}_{2}$ (JRC-CEO-2, $S_{\mathrm{BET}}=123.1 \mathrm{~m}^{2} \mathrm{~g}^{-1}$ ), $\mathrm{ZrO}_{2}$ (JRC-ZRO-6, $\left.S_{\mathrm{BET}}=279.3 \mathrm{~m}^{2} \mathrm{~g}^{-1}\right)$, and $\mathrm{TiO}_{2}\left(\mathrm{P}-25\right.$, anatase). $\mathrm{MgAl}_{2} \mathrm{O}_{4}$ support was prepared by a co-precipitation method using urea as a precipitating agent. The precursors and urea were precisely weighted and dissolved together in deionized water so that urea/precursors atomic ratio was 20. Mixed aqueous solution of $\mathrm{Mg}\left(\mathrm{NO}_{3}\right)_{3} \cdot 6 \mathrm{H}_{2} \mathrm{O}$, $\mathrm{Al}\left(\mathrm{NO}_{3}\right)_{3} \cdot 9 \mathrm{H}_{2} \mathrm{O}$ and urea was stirred overnight at $90^{\circ} \mathrm{C}$. After the precipitation, the solution was washed with water five times and dried overnight in oven at $90^{\circ} \mathrm{C}$, followed by calcination at $800{ }^{\circ} \mathrm{C}$ in the dry air for $5 \mathrm{~h}$. $\mathrm{CeZrO}_{2}$ and $\mathrm{CaZrO}_{3}$ were prepared in a same co-precipitation method used to prepare $\mathrm{MgAl}_{2} \mathrm{O}_{4}$. Ce $\left(\mathrm{NO}_{3}\right)_{3} \cdot 6 \mathrm{H}_{2} \mathrm{O}, \mathrm{Zr}\left(\mathrm{NO}_{3}\right)_{2} \mathrm{O} \cdot 2 \mathrm{H}_{2} \mathrm{O}$, and $\mathrm{Ca}\left(\mathrm{NO}_{3}\right)_{2} \cdot 4 \mathrm{H}_{2} \mathrm{O}$ were used as precursors.

Catalyst preparation. (1) Pt-based bimetallic catalysts were prepared by the porefilling co-impregnation method using $\mathrm{SiO}_{2}$ as the support $\left(\mathrm{Pt}_{3} \mathrm{M} / \mathrm{SiO}_{2}\right.$, and $\mathrm{PtM} /$ $\mathrm{SiO}_{2}$, where $\mathrm{M}=\mathrm{Ga}$, In, $\mathrm{Sn}$, and Pb; Pt: 3 wt\%). $\mathrm{Ga}\left(\mathrm{NO}_{3}\right)_{3} \cdot n \mathrm{H}_{2} \mathrm{O}(n=7-9), \mathrm{SnCl}_{2}$, $\mathrm{Pb}\left(\mathrm{NO}_{3}\right)_{2}$ were used as second metal precursors. The ratio of precursors was fixed at the desired ratio. Mixed aqueous solution of $\mathrm{Pt}\left(\mathrm{NH}_{3}\right)_{2}\left(\mathrm{NO}_{2}\right)_{2}$ and second metal was added dropwise to ground dried $\mathrm{SiO}_{2}$ so that the solutions just filled the pores of the $\mathrm{SiO}_{2}$. The mixture was kept in a sealed round-bottom flask overnight at room temperature, followed by quick freezing with liquid nitrogen, freeze-drying in vacuum at $-5^{\circ} \mathrm{C}$. The resulting powder was further dried in an oven at $90^{\circ} \mathrm{C}$ overnight, calcined in dry air at $400^{\circ} \mathrm{C}$ for $1 \mathrm{~h}$, and finally reduced by $\mathrm{H}_{2}(0.1 \mathrm{MPa}$, $50 \mathrm{~mL} \mathrm{~min}^{-1}$ ) at $700{ }^{\circ} \mathrm{C}$ for $1 \mathrm{~h}$. The catalysts except $\mathrm{Pt} / \mathrm{SiO}_{2}$ were further annealed at $400{ }^{\circ} \mathrm{C}$ for $2 \mathrm{~h}$ under flowing $\mathrm{H}_{2}\left(0.1 \mathrm{MPa}, 50 \mathrm{~mL} \mathrm{~min}^{-1}\right)$ to enhance alloying without further sintering. $\mathrm{Ga} / \mathrm{SiO}_{2}$ catalyst with $5 \mathrm{wt} \%$ loading was prepared using a similar method (reduction was carried out at $900^{\circ} \mathrm{C}$ for $1 \mathrm{~h}$ ). (2) The corresponding silica-supported trimetallic catalysts were also prepared using a similar method for $\mathrm{PtGa} / \mathrm{SiO}_{2}\left[\mathrm{PtGa}-\mathrm{Pb} / \mathrm{SiO}_{2}\right.$, where $\mathrm{Pt} / \mathrm{Pb}=5,2.5,2$, and 1.5; PtGa-M/ $\mathrm{SiO}_{2}$, where $\mathrm{M}=\mathrm{In}$ and $\left.\mathrm{Sn}, \mathrm{Pt} / \mathrm{M}=2 ; \mathrm{Pt}: 3 \mathrm{wt} \%\right] . \mathrm{In}\left(\mathrm{NO}_{3}\right)_{3} \cdot 8.8 \mathrm{H}_{2} \mathrm{O}$ (determined by ICP-AES), $\mathrm{SnCl}_{2}$, and $\mathrm{Pb}\left(\mathrm{NO}_{3}\right)_{2} \cdot 6 \mathrm{H}_{2} \mathrm{O}$ were used as third metal precursors. (3) A series of $\mathrm{Pt}-\mathrm{Ga}$ bimetallic catalysts supported on various oxides $(\mathrm{PtGa} / \mathrm{X}$, where $X=\gamma-\mathrm{Al}_{2} \mathrm{O}_{3}, \mathrm{MgAl}_{2} \mathrm{O}_{4}, \mathrm{CeO}_{2}, \mathrm{CeZrO}_{2}, \mathrm{ZrO}_{2}, \mathrm{CaZrO}_{3}$, and $\mathrm{TiO}_{2} ; \mathrm{Pt} / \mathrm{Ga}=1 ; \mathrm{Pt}$ : $3 \mathrm{wt} \%$ ) was prepared by the conventional impregnation method. To prepare the precursor solution, $\mathrm{Pt}\left(\mathrm{NH}_{3}\right)_{2}\left(\mathrm{NO}_{3}\right)_{2}$ and $\mathrm{Ga}\left(\mathrm{NO}_{3}\right)_{3} \cdot n \mathrm{H}_{2} \mathrm{O}(n=7-9)$ were dissolved in an excess amount of water (ca. $25 \mathrm{~mL}$ of ion exchanged water per $\mathrm{g}$ of support). The oxide support was added to a vigorously stirred aqueous solution of the metal precursors and kept with stirring at $90^{\circ} \mathrm{C}$ for $3 \mathrm{~h}$. The mixture was dried using a rotary evaporator at $50^{\circ} \mathrm{C}$ and further dried overnight in an oven at $90^{\circ} \mathrm{C}$. The resulting powder was treated in a similar manner for the $\mathrm{SiO}_{2}$-supported alloy catalysts as mentioned above.

Catalytic reaction. PDH was carried out in a vertical, quartz fixed-bed reactor with $6 \mathrm{~mm}$ of internal diameter under an atmospheric pressure. Generally, $15 \mathrm{mg}$ of catalysts diluted with quartz sand (total: $1.5 \mathrm{~g}$ ) were charged in the reactor. For the experiments in Fig. 4, the catalyst amount was adjusted so that the number of exposed Pt was identical $(4.5 \mu \mathrm{mol})$ : $\mathrm{PtGa}(9.0 \mathrm{mg}), \mathrm{PtGa}-\mathrm{Pb}(15 \mathrm{mg}), \mathrm{Pt}_{3} \mathrm{Sn}$ $(3.7 \mathrm{mg})$. Prior to the catalytic test, the catalyst was prereduced under flowing $\mathrm{H}_{2}$ at $650{ }^{\circ} \mathrm{C}$ and held at $650^{\circ} \mathrm{C}$ for $0.5 \mathrm{~h}$. After the pretreatment, the temperature was kept at $650{ }^{\circ} \mathrm{C}$ or decreased to $600{ }^{\circ} \mathrm{C}$, followed by feeding reactant gas mixture; $\mathrm{C}_{3} \mathrm{H}_{8}: \mathrm{H}_{2}: \mathrm{He}=3.9: 5: 40$, a total of $48.9 \mathrm{~mL} \mathrm{~min}^{-1}$ (WHSV $\left.=30.7 \mathrm{~h}^{-1}\right)$. The result ing product gas was analyzed by online thermal conductivity detector (TCD) gas chromatograph (Shimadzu GC-8A with a column of Unipak S, GL Science) equipped downstream. For all the catalysts, $\mathrm{C}_{3} \mathrm{H}_{8}, \mathrm{C}_{2} \mathrm{H}_{4}, \mathrm{C}_{2} \mathrm{H}_{6}$, and $\mathrm{CH}_{4}$ were detected as reaction products. The $\mathrm{C}_{3} \mathrm{H}_{8}$ conversion, $\mathrm{C}_{3} \mathrm{H}_{6}$ selectivity, $\mathrm{C}_{3} \mathrm{H}_{8}$ yield, and material balance were defined by Eqs. (1)-(4), respectively. Material balance typically ranged between $95 \%$ and $105 \%$ for all the reactions.

$$
\begin{gathered}
\mathrm{C}_{3} \mathrm{H}_{8} \text { conversion }(\%)=\frac{\left[\mathrm{C}_{3} \mathrm{H}_{8}\right]_{\text {inlet }}-\left[\mathrm{C}_{3} \mathrm{H}_{8}\right]_{\text {outlet }}}{\left[\mathrm{C}_{3} \mathrm{H}_{8}\right]_{\text {inlet }}} \times 100 \\
\mathrm{C}_{3} \mathrm{H}_{6} \text { selectivity }(\%)=\frac{\left[\mathrm{C}_{3} \mathrm{H}_{6}\right]}{\left[\mathrm{C}_{3} \mathrm{H}_{6}\right]+\frac{2}{3}\left[\mathrm{C}_{2} \mathrm{H}_{6}\right]+\frac{2}{3}\left[\mathrm{C}_{3} \mathrm{H}_{4}\right]+\frac{1}{3}\left[\mathrm{CH}_{4}\right]} \times 100 \\
\text { Material balance }(\%)=\frac{\left[\mathrm{C}_{3} \mathrm{H}_{6}\right]_{\text {outlet }}+\left[\mathrm{C}_{3} \mathrm{H}_{6}\right]+\frac{2}{3}\left[\mathrm{C}_{2} \mathrm{H}_{6}\right]+\frac{2}{3}\left[\mathrm{C}_{2} \mathrm{H}_{4}\right]+\frac{1}{3}\left[\mathrm{CH}_{4}\right]}{\left[\mathrm{C}_{3} \mathrm{H}_{8}\right]_{\text {inlet }}} \times 100
\end{gathered}
$$

Characterization. XRD patterns of the Pt-based catalysts were obtained using a MiniFlex 700+D/teX Ultra (X-ray source: $\mathrm{Cu} K a$ radiation). HAADF-STEM analysis was performed by an FEI Titan G2 or a JEOL JEM-ARM200 M microscope with an EDX detector. The volume averaged particle size in a TEM image $\left(d_{\text {TEM }}\right)$ was obtained by the following equation:

$$
d_{\mathrm{TEM}}=\frac{\sum_{i} n_{i} d_{i}^{4}}{\sum_{i} n_{i} d_{i}^{3}},
$$

where $n_{i}$ and $d_{i}$ indicate the number of particles (having the size of $d_{i}$ ) and the particle diameter, respectively.

Pt dispersion in the catalysts (percentage of exposed Pt to the total amount of $\mathrm{Pt}$ ) was measured by chemisorption of $\mathrm{CO}$ at room temperature. Prior to chemisorption, the catalyst $(50 \mathrm{mg})$ was treated by $5 \% \mathrm{H}_{2} / \mathrm{Ar}\left(40 \mathrm{~mL} \mathrm{~min}^{-1}\right)$ at $300{ }^{\circ} \mathrm{C}$ for $0.5 \mathrm{~h}$, followed by cooling to room temperature with an He purge $\left(40 \mathrm{~mL} \mathrm{~min}^{-1}\right)$ to remove chemisorbed hydrogen. We introduced a pulse of $10 \%$ $\mathrm{CO} / \mathrm{He}$ into the reactor and quantified the $\mathrm{CO}$ passed through the catalyst bed using a TCD detector. This pulse measurement was repeated until no more CO was adsorbed. We estimated the amount of chemisorbed $\mathrm{CO}$ assuming a 1:1 stoichiometry for CO chemisorption on a surface Pt atom.

XPS study was conducted using a JEOL JPS-9010MC spectrometer (X-ray source: $\mathrm{Mg}-\mathrm{Ka}$ radiation). The catalysts were treated by flowing $\mathrm{H}_{2}$ at $650^{\circ} \mathrm{C}$ for $0.5 \mathrm{~h}$ in a quartz reactor, followed by transferring into the spectrometer in air. The surface of the catalyst was sputtered by $\mathrm{Ar}^{+}$(voltage: $400 \mathrm{~V}$, rate: $20 \%$, time: $1 \mathrm{~s}$, at each cycle) for the depth analysis. Calibration of the binding energy was performed with the $\mathrm{Si} 2 p$ emission of the $\mathrm{SiO}_{2}$ support $(103.9 \mathrm{eV})$. 
FT-IR spectra of adsorbed CO were obtained with a JASCO FTIR-4100 spectrometer with a TGS detector in the transmission mode (resolution $4 \mathrm{~cm}^{-1}$ ) under a dynamic condition. Prior to $\mathrm{CO}$ chemisorption, $50 \mathrm{mg}$ of the catalyst was pressed into a pellet (diameter of $20 \mathrm{~mm}$ ) and placed in a quartz cell equipped with $\mathrm{CaF}_{2}$ windows and a Dewar vessel, followed by reduction under a flowing $\mathrm{H}_{2}$ at $550{ }^{\circ} \mathrm{C}$ for $1 \mathrm{~h}$. The reduced sample was then kept in vacuum at $550{ }^{\circ} \mathrm{C}$ for $1 \mathrm{~h}$, then the cell was cooled to $\mathrm{ca}-196^{\circ} \mathrm{C}$ by liquid nitrogen. The sample was exposed to a pulse of low-pressure $\mathrm{CO}$, and then evacuated in vacuum to remove the gaseous $\mathrm{CO}$ and concentrated $\mathrm{CO}$ on the catalyst. This $\mathrm{CO}$ exposure was repeated several times until the $\mathrm{CO}$ saturation coverage.

TPO experiment was performed to quantify the amount of coke deposited on the spent catalysts after $20 \mathrm{~h}$ of PDH at $600{ }^{\circ} \mathrm{C}(15 \mathrm{mg}$ of the catalyst without quartz sand). The spent catalyst $(10 \mathrm{mg}$ ) placed in a quartz tube reactor was treated under flowing $\mathrm{He}\left(40 \mathrm{~mL} \mathrm{~min}^{-1}\right)$ at $150^{\circ} \mathrm{C}$ for $30 \mathrm{~min}$, followed by cooling to room temperature. Then, the catalyst bed temperature was increased $\left(25-900^{\circ} \mathrm{C}\right.$, ramping rate: $\left.5^{\circ} \mathrm{C} \mathrm{min}-1\right)$ under flowing $\mathrm{O}_{2} / \mathrm{He}\left(50 \%, 40 \mathrm{~mL} \mathrm{~min}^{-1}\right)$. The amount of $\mathrm{CO}_{2}$ in the outlet gas was quantified by an online mass spectrometer.

XAFS spectra of the prepared catalysts were collected at the BL01B1 beamline of SPring-8, Japan Synchrotron Radiation Research Institute (JASRI) using an $\mathrm{Si}(111)$ double-crystal as a monochromator. Prior to the measurement, the catalyst was pelletized (ca. $150 \mathrm{mg}$ with a diameter of $10 \mathrm{~mm}$ ) and pretreated by $\mathrm{H}_{2}$ at $650{ }^{\circ} \mathrm{C}$ for $0.5 \mathrm{~h}$ in a quartz tube. After the pretreatment, the quartz tube containing the reduced pellet was sealed and transferred into an Ar grove box $\left(\mathrm{O}_{2}:<0.1 \mathrm{ppm}\right)$ without exposing to air. The pellet was sealed in a plastic film bag (Barrier Nylon) together with an oxygen absorber (ISO A500-HS: Fe powder). The Pt $\mathrm{L}_{\mathrm{III}}{ }^{-}$and Ga $\mathrm{K}$-edges XAFS spectra were recorded in a transmission mode at room temperature. Athena and Artemis software ver. 0.9.25 implemented in the Demeter package ${ }^{35}$ was used for the analysis of the obtained XAFS spectra. Fourier-transform of the Pt $\mathrm{L}_{\text {III- }}$-edge EXAFS oscillation was obtained in the $k$ range of $3-16 \AA^{-1}$. The back Fourier-transform obtained in the $R$ range of 1.5-3.5 $\AA$ was used for curve-fitting. FEFF8 was used for the calculation of the back-scattering amplitude and phase shift functions ${ }^{36}$. We defined the $R$-factor $\left(R^{2}\right)$ for curve-fitting as follows:

$$
R^{2}=\Sigma_{i}\left\{k^{3} \chi_{i}^{\exp }(k)-k^{3} \chi_{i}^{\text {fit }}(k)\right\}^{2} \operatorname{per} \Sigma_{i}\left\{k^{3} \chi_{i}^{\exp }(k)\right\}^{2} .
$$

Computational details. DFT calculations were performed by using the CASTEP $\operatorname{code}^{37}$. We used Vanderbilt-type ultrasoft pseudopotentials ${ }^{38}$ and the revised version of Perdew-Burke-Ernzerhof exchange-correlation functional ${ }^{39,40}$ based on the generalized gradient approximation. A cut-off energy of $370 \mathrm{eV}$ was used for the plane-wave basis set. A $k$-point mesh with a spacing of $0.04 \AA^{-1}$ generated by the Monkhorst-Pack scheme ${ }^{41}$ was used to sample the Brillouin zone. In this study, the $\mathrm{PtGa}: \mathrm{A}(111)$ and $\mathrm{Pt}_{3} \mathrm{Sn}(111)$ planes were considered as the standard active surfaces for PDH. The supercell structure was constructed using a $(2 \times 2)$ unit cell slab with six atomic layers and a vacuum spacing of $15 \AA$. We performed geometry optimizations on the supercell structures using a Fermi smearing of $0.1 \mathrm{eV}$, the OBS method for dispersion correlations, and the following convergence criteria: (1) self-consistent field tolerance: $1.0 \times 10^{-6} \mathrm{eV}$ per atom; (2) energy tolerance: $1.0 \times 10^{-5} \mathrm{eV}$ per atom; (3) maximum force tolerance of $0.05 \mathrm{eV} \AA^{-1}$, and (4) maximum displacement tolerance: $1.0 \times 10^{-3} \AA$. Transition state search was carried out based on the complete linear synchronous transit/quadratic synchronous transit method ${ }^{42,43}$ with the tolerance for all root-mean-square forces on an atom of $0.10 \mathrm{eV}^{-1}$.

\section{Data availability}

The data that support the findings of this study are available from the corresponding author upon reasonable request.

Received: 11 March 2020; Accepted: 15 May 2020;

Published online: 05 June 2020

\section{References}

1. Sattler, J. J. H. B., Ruiz-Martinez, J., Santillan-Jimenez, E. \& Weckhuysen, B. M. Catalytic dehydrogenation of light alkanes on metals and metal oxides. Chem. Rev. 114, 10613-10653 (2014)

2. James, O. O., Mandal, S., Alele, N., Chowdhury, B. \& Maity, S. Lower alkanes dehydrogenation: strategies and reaction routes to corresponding alkenes. Fuel Process. Technol. 149, 239-255 (2016).

3. Hu, Z. P., Yang, D., Wang, Z. \& Yuan, Z. Y. State-of-the-art catalysts for direct dehydrogenation of propane to propylene. Chin. J. Catal. 40, 1233-1254 (2019).

4. Bhasin, M. M., McCain, J. H., Vora, B. V., Imai, T. \& Pujadó, P. R. Dehydrogenation and oxydehydrogenation of paraffins to olefins. Appl. Catal. A Gen. 221, 397-419 (2001).

5. Sanfilippo, D. \& Miracca, I. Dehydrogenation of paraffins: synergies between catalyst design and reactor engineering. Catal. Today 111, 133-139 (2006).
6. Hauser, A. W., Horn, P. R., Head-Gordon, M. \& Bell, A. T. A systematic study on Pt based, subnanometer-sized alloy cluster catalysts for alkane dehydrogenation: effects of intermetallic interaction. Phys. Chem. Chem. Phys. 18, 10906-10917 (2016)

7. Yang, M. L., Zhu, Y. A., Zhou, X. G., Sui, Z. J. \& Chen, D. First-principles calculations of propane dehydrogenation over PtSn catalysts. ACS Catal. 2 $1247-1258$ (2012).

8. Zha, S. et al. Identification of Pt-based catalysts for propane dehydrogenation: via a probability analysis. Chem. Sci. 9, 3925-3931 (2018).

9. Zhao, Z. J., Chiu, C. C. \& Gong, J. Molecular understandings on the activation of light hydrocarbons over heterogeneous catalysts. Chem. Sci. 6, 4403-4425 (2015).

10. Nykänen, L. \& Honkala, K. Selectivity in propene dehydrogenation on Pt and $\mathrm{Pt}_{3} \mathrm{Sn}$ surfaces from first principles. ACS Catal. 3, 3026-3030 (2013).

11. Sun, G. et al. Breaking the scaling relationship via thermally stable $\mathrm{Pt} / \mathrm{Cu}$ single atom alloys for catalytic dehydrogenation. Nat. Commun. 9, 4454 (2018).

12. Yang, X. F. et al. Single-atom catalysts: a new frontier in heterogeneous catalysis. Acc. Chem. Res. 46, 1740-1748 (2013).

13. Zhang, $\mathrm{Z}$. et al. Thermally stable single atom $\mathrm{Pt} / \mathrm{m}-\mathrm{Al}_{2} \mathrm{O}_{3}$ for selective hydrogenation and CO oxidation. Nat. Commun. 8, 16100 (2017).

14. Jones, J. et al. Thermally stable single-atom platinum-on-ceria catalysts via atom trapping. Science 353, 150-154 (2016).

15. Lin, L. et al. A highly CO-tolerant atomically dispersed Pt catalyst for chemoselective hydrogenation. Nat. Nanotechnol. 14, 354 (2019).

16. Marcinkowski, M. D. et al. Pt/Cu single-atom alloys as coke-resistant catalysts for efficient C-H activation. Nat. Chem. 10, 325-332 (2018).

17. Duan, S., Wang, R. \& Liu, J. Stability investigation of a high number density $\mathrm{Pt}_{1} / \mathrm{Fe}_{2} \mathrm{O}_{3}$ single-atom catalyst under different gas environments by HAADFSTEM. Nanotechnology 29, 204002 (2018).

18. Liu, W. E. \& Mohney, S. E. Condensed phase equilibria in transition metal$\mathrm{Ga}-\mathrm{Sb}$ systems and predictions for thermally stable contacts to GaSb. J. Electron. Mater. 32, 1090-1099 (2003).

19. Furukawa, S. \& Komatsu, T. Intermetallic compounds: promising inorganic materials for well-structured and electronically modified reaction environments for efficient catalysis. ACS Catal. 7, 735-765 (2017)

20. Prinz, J. et al. Adsorption of small hydrocarbons on the three-fold PdGa surfaces: the road to selective hydrogenation. J. Am. Chem. Soc. 136, 11792-11798 (2014)

21. Prinz, J. et al. Ensemble effect evidenced by $\mathrm{CO}$ adsorption on the 3 -fold PdGa surfaces. J. Phys. Chem. C 118, 12260-12265 (2014).

22. Bhargava, M. K., Gadalla, A. A. \& Schubert, K. Koexistente phasen vom FeSiTyp in den mischungen Ni-Pd-Ga und Ni-Pt-Ga. J. Less Common Met. 42, 69-76 (1975)

23. Iihama, S., Furukawa, S. \& Komatsu, T. Efficient catalytic system for chemoselective hydrogenation of halonitrobenzene to haloaniline using PtZn intermetallic compound. ACS Catal. 6, 742-746 (2016).

24. Buekens, A. G. \& Froment, G. F. Thermal cracking of propane: kinetics and product distributions. Ind. Eng. Chem. Process Des. Dev. 7, 435-447 (1968).

25. Nykänen, L. \& Honkala, K. Density functional theory study on propane and propene adsorption on Pt(111) and PtSn alloy surfaces. J. Phys. Chem. C. 115, 9578-9586 (2011)

26. Slater, J. C. Atomic radii in crystals. J. Chem. Phys. 41, 3199-3204 (1964).

27. Searles, K. et al. Highly productive propane dehydrogenation catalyst using silica-supported Ga-Pt nanoparticles generated from single-sites. J. Am. Chem. Soc. 140, 11674-11679 (2018).

28. Redekop, E. A. et al. Delivering a modifying element to metal nanoparticles via support: Pt-Ga alloying during the reduction of $\mathrm{Pt} / \mathrm{Mg}(\mathrm{Al}, \mathrm{Ga}) \mathrm{O}_{\mathrm{x}}$ catalysts and its effects on propane dehydrogenation. ACS Catal. 4, 1812-1824 (2014)

29. Wang, T. et al. Pyrolysis of heavy oil in the presence of supercritical water: the reaction kinetics in different phases. AIChE J. 61, 857-866 (2015).

30. Siddiqi, G., Sun, P., Galvita, V. \& Bell, A. T. Catalyst performance of novel Pt/ $\mathrm{Mg}(\mathrm{Ga})(\mathrm{Al}) \mathrm{O}$ catalysts for alkane dehydrogenation. J. Catal. 274, 200-206 (2010).

31. Im, J. \& Choi, M. Physicochemical stabilization of Pt against sintering for a dehydrogenation catalyst with high activity, selectivity, and durability. ACS Catal. 6, 2819-2826 (2016).

32. Jablonski, E. L., Castro, A. A., Scelza, O. A. \& De Miguel, S. R. Effect of Ga addition to $\mathrm{Pt} / \mathrm{Al}_{2} \mathrm{O}_{3}$ on the activity, selectivity and deactivation in the propane dehydrogenation. Appl. Catal. A Gen. 183, 189-198 (1999).

33. $\mathrm{Xu}, \mathrm{Y}$. et al. Sintering-resistant $\mathrm{Pt}$ on $\mathrm{Ga}_{2} \mathrm{O}_{3}$ rods for propane dehydrogenation: the morphology matters. Ind. Eng. Chem. Res. 57, 13087-13093 (2018).

34. Searles, K., Siddiqi, G., Safonova, O. V. \& Copéret, C. Silica-supported isolated gallium sites as highly active, selective and stable propane dehydrogenation catalysts. Chem. Sci. 8, 2661-2666 (2017).

35. Ravel, B. \& Newville, M. ATHENA, ARTEMIS, HEPHAESTUS: Data analysis for X-ray absorption spectroscopy using IFEFFIT. J. Synchrotron Radiat. 12, 537-541 (2005) 
36. Ankudinov, A. \& Ravel, B. Real-space multiple-scattering calculation and interpretation of x-ray-absorption near-edge structure. Phys. Rev. B 58, 7565-7576 (1998).

37. Segall, M. D. et al. First-principles simulation: Ideas, illustrations and the CASTEP code. J. Phys. Condens. Matter 14, 2717-2744 (2002).

38. Vanderbilt, D. Soft self-consistent pseudopotentials in a generalized eigenvalue formalism. Phys. Rev. B 41, 7892-7895 (1990).

39. Zhang, Y. \& Yang, W. Comment on "generalized gradient approximation made simple”. Phys. Rev. Lett. 80, 890 (1998).

40. Hammer, B., Hansen, L. B. \& Nørskov, J. K. Improved adsorption energetics within density-functional theory using revised Perdew-Burke-Ernzerhof functionals. Phys. Rev. B 59, 7413-7421 (1999).

41. Monkhorst, H. J. \& Pack, J. D. Special points for Brillouin-zone integrations. Phys. Rev. B 13, 5188-5192 (1976).

42. Halgren, T. A. \& Lipscomb, W. N. The synchronous-transit method for determining reaction pathways and locating molecular transition states. Chem. Phys. Lett. 49, 225-232 (1977).

43. Govind, N., Petersen, M., Fitzgerald, G., King-Smith, D. \& Andzelm, J. A generalized synchronous transit method for transition state location. Comput. Mater. Sci. 28, 250-258 (2003).

\section{Acknowledgements}

This work was supported by JSPS KAKENHI (Grant Numbers 17H01341, 17H04965, and 20H02517), MEXT project Element Strategy Initiative (JPMXP0112101003), JST CREST (JPMJCR17J3), and JST PRESTO (JPMJPR19T7). The XAFS analysis was performed with the approval of JASRI (No. 2019B1620 and 2019B1469). We appreciate the technical staffs of the faculty of engineering, Hokkaido University and of Research Institute for Electronic Science, Hokkaido University for help with HAADF-STEM observation. Computation time was provided by the supercomputer systems in Institute for Chemical Research, Kyoto University.

\section{Author contributions}

S.F. and Y.N. design the research and co-wrote the manuscript in discussion. Y.N. performed most of the experimetal works. J.H. and S.Y. carried out the XAFS analysis.
S.F. conducted the computational studies. S.F., Y.N., J.H., S.Y., and K.S. discussed the data and commented on the manuscript.

\section{Competing interests}

The authors declare no competing interests.

\section{Additional information}

Supplementary information is available for this paper at https://doi.org/10.1038/s41467020-16693-9.

Correspondence and requests for materials should be addressed to S.F.

Peer review information Nature Communications thanks Matthew Darby and the other, anonymous, reviewer(s) for their contribution to the peer review of this work. Peer reviewer reports are available.

Reprints and permission information is available at http://www.nature.com/reprints

Publisher's note Springer Nature remains neutral with regard to jurisdictional claims in published maps and institutional affiliations.

cc (i) Open Access This article is licensed under a Creative Commons Attribution 4.0 International License, which permits use, sharing, adaptation, distribution and reproduction in any medium or format, as long as you give appropriate credit to the original author(s) and the source, provide a link to the Creative Commons license, and indicate if changes were made. The images or other third party material in this article are included in the article's Creative Commons license, unless indicated otherwise in a credit line to the material. If material is not included in the article's Creative Commons license and your intended use is not permitted by statutory regulation or exceeds the permitted use, you will need to obtain permission directly from the copyright holder. To view a copy of this license, visit http://creativecommons.org/licenses/by/4.0/.

(C) The Author(s) 2020 